This item was submitted to Loughborough's Research Repository by the author.

Items in Figshare are protected by copyright, with all rights reserved, unless otherwise indicated.

\title{
Electromagnetic simulation studies of microwave assisted heating for the processing of nanostructured iron oxide for solar driven water splitting
}

PLEASE CITE THE PUBLISHED VERSION

http://dx.doi.org/10.1016/j.apsusc.2013.01.124

PUBLISHER

(C) Elsevier B.V.

VERSION

AM (Accepted Manuscript)

LICENCE

CC BY-NC-ND 4.0

\section{REPOSITORY RECORD}

Saremi-Yarahmadi, Sina, W.G. Whittow, and Bala Vaidhyanathan. 2019. "Electromagnetic Simulation Studies of Microwave Assisted Heating for the Processing of Nanostructured Iron Oxide for Solar Driven Water Splitting". figshare. https://hdl.handle.net/2134/12471. 
This item was submitted to Loughborough's Institutional Repository (https://dspace.lboro.ac.uk/) by the author and is made available under the following Creative Commons Licence conditions.

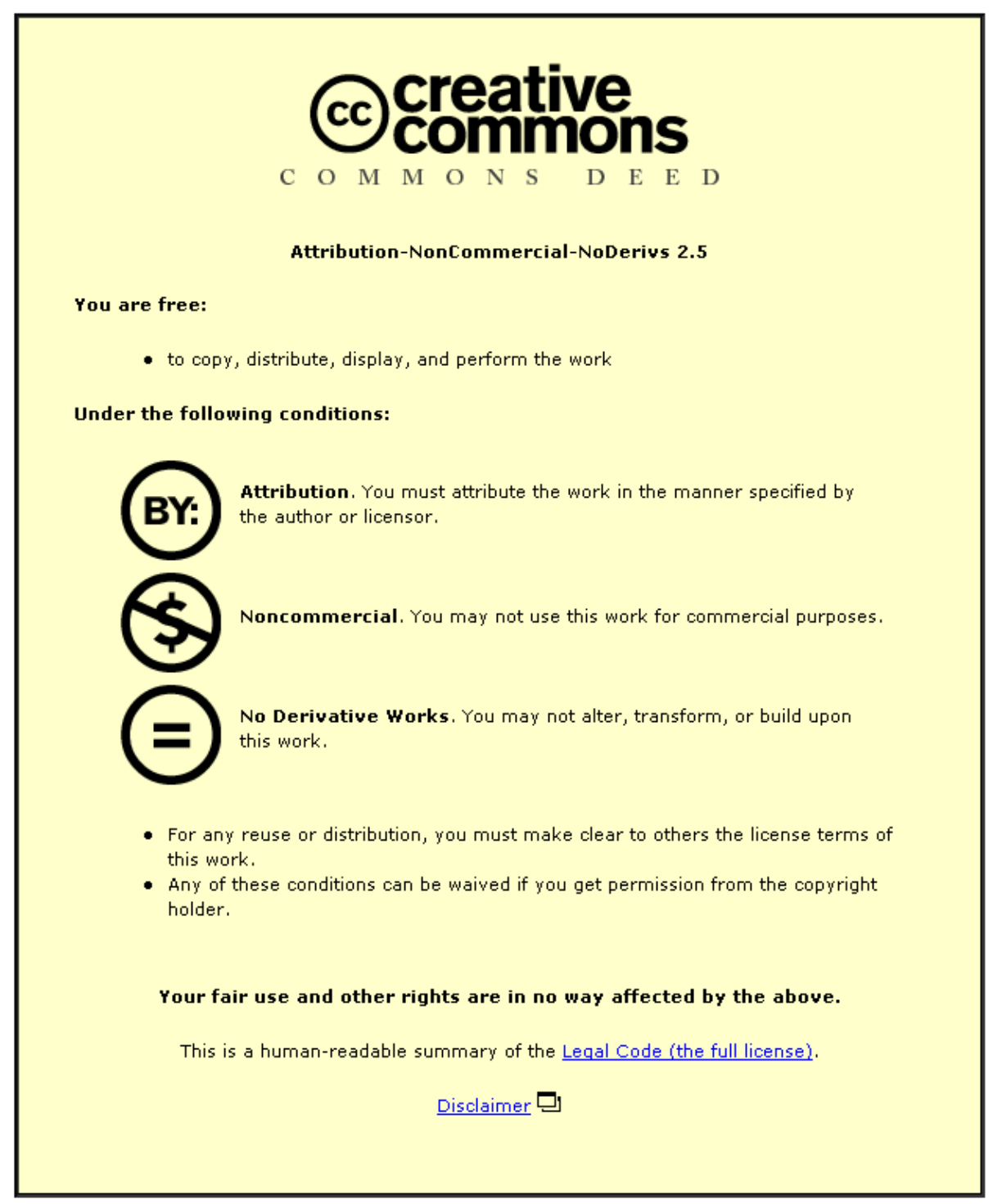

For the full text of this licence, please go to: http://creativecommons.org/licenses/by-nc-nd/2.5/ 
Final author version:

Elsevier Applied Surface Science, vol. 275, no. June, pp. 65-70, 2013.

\title{
Electromagnetic simulation studies of microwave assisted heating for the processing of nanostructured iron oxide for solar driven water splitting
}

\author{
S. Saremi-Yarahmadi ${ }^{1 *}$, W. Whittow ${ }^{2}$, B. Vaidhyanathan ${ }^{1}$ \\ ${ }^{1}$ Department of Materials, Loughborough University, Loughborough, LE11 3TU, UK \\ ${ }^{2}$ School of Electronic, Electrical and Systems Engineering, Loughborough University, \\ Loughborough, LE11 3TU, UK
}

\begin{abstract}
Microwave assisted preparation has been shown to improve the performance of hematite photoelectrodes for solar driven water splitting. To understand the microwave heating process further, the distribution of the electromagnetic (EM) fields within the material is analysed using finite-difference time-domain (FDTD) EM software. The rate of the increase in temperature is calculated from the simulated EM field distributions. In order to validate the simulation results, the calculated temperatures were compared with the experimental temperatures obtained using a thermal imaging camera.
\end{abstract}

Keywords: electric field distribution, simulation, nanostructured, microwave

\section{Introduction}

Generation of hydrogen through photoelectrochemcial (PEC) water splitting is one of the most promising alternatives for the production of hydrogen as a fuel. In this method, light is absorbed by a semiconductor electrode which then provides the energy required to break water molecules into hydrogen and oxygen. So far a variety of semiconductor materials such as $\mathrm{TiO}_{2}[1-3], \mathrm{SrTiO}_{3}[4]$, $\mathrm{CdS}[5,6], \mathrm{WO}_{3}[7,8]$ and $\mathrm{Fe}_{2} \mathrm{O}_{3}[9,10]$ has been used as PEC water splitting photoelectrodes. The desirable material capable of driving the reactions involved in the photocatalysis of water is required to satisfy several requirements; suitable bandgap, favourable positioning of the band edge energy levels,

\footnotetext{
* Corresponding author. Tel.: +44 1509223168 ; Fax: +44 1509223949.

E-mail address: S.Saremi@lboro.ac.uk.
} 


\section{Final author version:}

Elsevier Applied Surface Science, vol. 275, no. June, pp. 65-70, 2013.

stability in aqueous environment, abundance and ease of fabrication are considered to be the most important [11].

Hematite $\left(\alpha-\mathrm{Fe}_{2} \mathrm{O}_{3}\right)$ is a strong candidate photoelectrode for PEC water splitting as it meets most of the selection criteria of a suitable material for this application such as bandgap, chemical and PEC stability, and ease of fabrication. However, one of the major barriers in the development of efficient hematite photoelectrodes is the short hole diffusion length in hematite $(2-4 \mathrm{~nm})$ hence poor hole transport at the hematite/electrolyte interface[17,18]. As a result, photocurrent densities and conversion efficiencies reported for undoped hematite electrodes have not been promising.

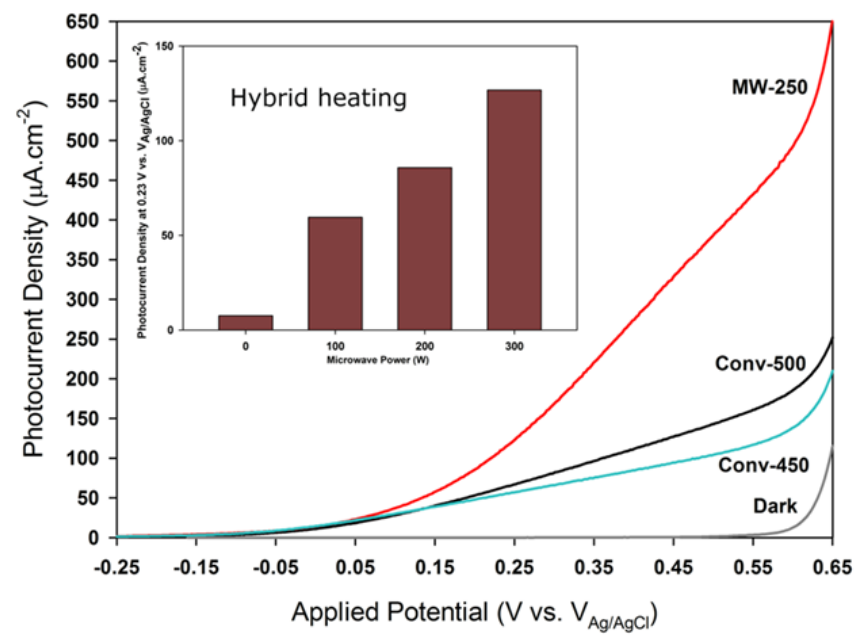

Figure 1. Graph showing the photocurrent density vs. applied potential for the undoped samples annealed using conventional (Conv) and microwave heating (MW). Samples were annealed for 15 minutes at 250, 450 and 500 ${ }^{\circ} \mathrm{C}$ [16]. Inset) The bar chart showing the linear increase of the photocurrent density at $0.23 \mathrm{~V} \mathrm{vs}$. $\mathrm{V}_{\mathrm{Ag} / \mathrm{AgCl}}$ of hematite photoelectrodes (heated at $500{ }^{\circ} \mathrm{C}$ for 30 minutes) as a function of microwave power applied in hybrid heating [23].

Microwave irradiation has shown great potential for the processing of different inorganic solids [19]. The use of microwave irradiation in processing of materials has been shown to offer several advantages such as shorter synthesis time, higher yields, better particle shape control and chemical plant size reduction [20-22]. Recently, we reported a facile microwave assisted route for the fabrication of iron oxide photoelectrodes which showed 


\section{Final author version:}

Elsevier Applied Surface Science, vol. 275, no. June, pp. 65-70, 2013.

improved PEC performance $[16,23]$. We showed for the first time that the conversion of iron into iron oxide using a microwave assisted process occurred at lower temperatures and at faster times than what had been previously reported [16]. It was also demonstrated that the less demanding processing conditions associated with the microwave approach combined with the specific advantage of rapid heating and cooling. The performance of microwave-prepared films surpassed that of the samples annealed conventionally while a total energy savings of $>60 \%$ was achieved [16]. For example, as shown in Fig. 1, the highest photocurrent density at $0.55 \mathrm{~V}$ vs. $\mathrm{V}_{\mathrm{Ag} / \mathrm{AgCl}}$, before the dark current onset, was $\sim 400 \mu \mathrm{A} . \mathrm{cm}^{-2}$ for the films annealed at $250{ }^{\circ} \mathrm{C}$ for 15 minutes using microwave irradiation while conventional annealing at the same temperature resulted in samples with negligible (3 $\mu$ A.cm-2) photoactivity [16].

In order to understand the specific role played by microwave we examined the effect of microwave power on the performance of nanostructured hematite photoelectrodes using hybrid heating [23]. This study confirmed the genuine and effective role of the microwave energy in improving the photo-performance of hematite electrodes; the photoperformance increased as more microwave power was applied at the same temperaturetime profiles (Figure 1 inset). The effectiveness of the role of microwave heating in improving the photo-performance (i.e. higher photocurrent density) was attributed to the following factors: i) improved surface properties of microwave heated films, i.e. less defective oxygen sub-lattice of hematite hence less surface recombination [23], ii) the retained nanostructure and minimised grain coalescence as a result of lower processing temperatures and rapidity of the process [16]. However, the interaction of electromagnetic (EM) field with the nanostructured film is not completely understood. To begin the understanding of the microstructural changes in the microwave assisted heating process, it is vital to determine the distribution of the EM fields within the material.

The finite-difference time-domain (FDTD) technique has been widely used to model electromagnetic fields since 1980 [24, 25] and its popularity has increased with the advancement of computational resources. Many papers have used electromagnetic 


\section{Final author version:}

Elsevier Applied Surface Science, vol. 275, no. June, pp. 65-70, 2013.

simulations to examine the heating of food and other objects inside a microwave oven [26-29]. FDTD is also a popular simulation tool for understanding microwave assisted sintering of ceramic components [30] and has been validated using analytical solutions [31] as well as finite element methods [32]. In this paper the distribution of EM field in the specific microwave oven is modelled using FDTD. It also compares consequently calculated rate of the temperature increase with experimental measurements.

\section{Methodology}

In this paper the distribution of electromagnetic fields in a bespoke commercial microwave oven is modelled. The simulated results were validated against with the rate of temperature increase with experimental measurements made using a thermal imaging camera.

Experimental setup - The microwave oven used (MC8087ARS multimode cavity, LG, Milton Keynes, UK) is capable of producing a tuneable continuous power output up to a maximum of $1000 \mathrm{~W}$ operating at $2.45 \mathrm{GHz}$ frequency. The microwave oven is fitted with thermal imaging camera (FLIR Thermovision A40, FLIR Systems, West Malling, UK) and hence the samples were centred below this: $110 \mathrm{~mm}$ from the door in the $\mathrm{Y}$ axis and centrally in the $\mathrm{X}$ axis. A $25 \mathrm{~mm}$ thick sample of porous meant the samples were raised $25 \mathrm{~mm}$ in the $\mathrm{Z}$ direction. Temperature was recorded using ThermaCAM Researcher software. In order to fabricate hematite electrodes using microwave heating, thin films of Fe were electrodeposited on fluorine-doped tin oxide coated (FTO, TEC8, Pilkington Glass, Ltd, St Helens, UK) glass substrates [16]. Then, microwave assisted thermal oxidation of iron films were carried out by placing the films inside a high purity alumina casket to minimise the heat loss. SiC rods were used as secondary susceptors [16]. The electric field distribution in this microwave oven is simulated in different steps so that the final configuration would match that of the experimental setup.

Simulation methodology - The FDTD method discretises the problem space into many small cuboids which define the sampling of the problem space and also the resolution of 


\section{Final author version:}

Elsevier Applied Surface Science, vol. 275, no. June, pp. 65-70, 2013.

the structure - these are called Yee cells. The Yee cell splits the electric and magnetic fields into their three Cartesian components forming a discretised 3-D space lattice, see Figure 2. Each Yee cell can have its own dielectric or metallic properties and many of these Yee cells then tessellate together to build the required structure. The Yee cells should be less than $1 / 10^{\text {th }}$ of a wavelength to adequately sample the wave. Note, small Yee cells are required to model thin structures which increases the computational resources required. In a dielectric material, the relative permittivity, $\varepsilon_{r}$, is greater than 1 , the wavelength will be reduced by a factor of $\sqrt{ } \varepsilon_{r}$.

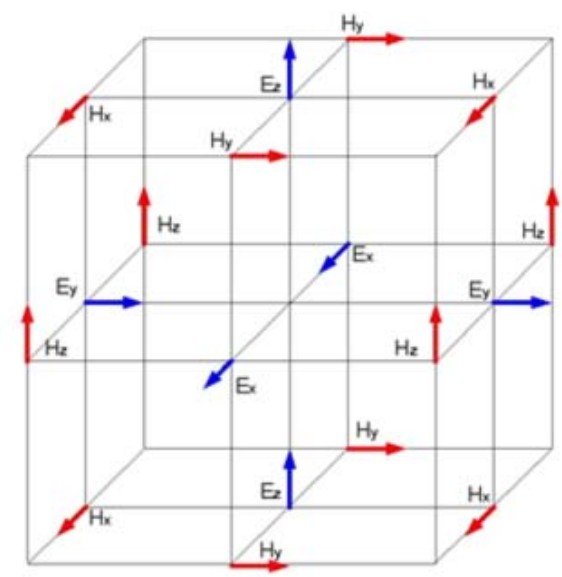

Figure 2. The Yee cell with six Cartesian electric (E) and magnetic field (H) components.

As FDTD works on the principle of nearest neighbour interactions, it is important for numerical stability that the wave does not propagate more than one Yee cell in each time period. This enforces a relationship between the size of the cell and the time step duration and is known as the Courant condition [24]. The electric and magnetic fields are calculated at alternate half time step intervals and are said to leapfrog each other in time. This process is continued until stability has been achieved. The electric and magnetic field values can be then found throughout this discretised space using the FDTD equations which can be easily derived from Maxwell's equations using second order accurate approximations for the finite differences [24,25]. The FDTD grid must be terminated with absorbing boundary conditions $(\mathrm{ABC})$ to stop reflections from the edges of the computational domain. 


\section{Final author version:}

Elsevier Applied Surface Science, vol. 275, no. June, pp. 65-70, 2013.

Specific absorption rate (SAR) is the term used to calculate the heating in the human body from electromagnetic fields $[33,34]$. This is the power absorbed per unit mass and the units are $\mathrm{W} / \mathrm{kg}$. This can also be used to calculate the heating of a non-biological object in a microwave oven:

$$
S A R=\frac{E^{2} \sigma}{\rho}=\frac{\Delta T}{\Delta t} C \quad \text { Eq.(3) }
$$

Where $\mathrm{E}$ is the root mean square electric field strength $(\mathrm{V} / \mathrm{m}) ; \sigma$ is the electrical conductivity $(\mathrm{S} / \mathrm{m}) ; \rho$ is the density $\left(\mathrm{kg} / \mathrm{m}^{3}\right) ; \Delta \mathrm{T}$ is the change in temperature $\left({ }^{\circ} \mathrm{C}\right) ; \Delta \mathrm{t}$ is the change in time (s) and $\mathrm{C}$ is the specific heat capacity $(\mathrm{J} / \mathrm{kgK})$. Therefore, the rate of temperature increase can be found from the simulated electric field values and the known values for the conductivity, density and the specific heat capacity.

In this paper, EMPIRE XCcel FDTD commercial software was used. The microwave oven was modelled with six metallic walls with a waveguide feed on the side wall. The simulated geometry is shown in Figure 3 to Figure 5.

The internal dimensions of the oven cavity are: length, $\mathrm{X}$ axis $=343 \mathrm{~mm}$; width, $\mathrm{Y}$ axis $=$ $341 \mathrm{~mm}$; height, $\mathrm{Z}$ axis $=220 \mathrm{~mm}$. The waveguide section has the following dimensions (internal): length, $\mathrm{X}$ axis $=250 \mathrm{~mm}$; width, $\mathrm{Y}$ axis $=86.4 \mathrm{~mm}$ and height, $\mathrm{Z}$ axis $=$ $43.2 \mathrm{~mm}$. The waveguide was initially tested in isolation and the cutoff frequency as determined by the dimensions was $1.74 \mathrm{GHz}$. The top of the waveguide was positioned $26.8 \mathrm{~mm}$ below the top face of the microwave oven and the side of the waveguide was positioned $25.6 \mathrm{~mm}$ from the side of the cavity. The cavity and waveguide walls were assumed to be perfect conductors and hence the leakage at the edge of the doors was assumed to be zero. The $25 \mathrm{~mm}$ thick porous alumina block on the microwave floor was simulated with a relative permittivity of 9.4 and a loss tangent of 0.005 . The same material was used for the casket in the $\mathrm{SiC}$, glass and FTO simulations. The simulated frequency was $2.45 \mathrm{GHz}$. The Yee cells were less than $1 / 20^{\text {th }}$ of a wavelength and smaller cell sizes were used for the finer structures. For example, the geometry with the FTO sample simulation required $472 \times 344 \times 168$ Yee cells with a timestep of $\sim 300 \mathrm{fS}$ and the 


\section{Final author version:}

Elsevier Applied Surface Science, vol. 275, no. June, pp. 65-70, 2013.

runtime was approximately 10 hours on a desktop computer. In all cases, the data was carefully checked to ensure that the results had fully converged to a stable value.

In order to validate the simulations results water and $\mathrm{SiC}$ susceptors were heated in this oven at the constant microwave power of $200 \mathrm{~W}$. The heating rate $(\Delta \mathrm{T} / \Delta \mathrm{t})$ was used as a calibration tool to validate simulation results. Once the validation was completed further simulation experiment was carried out by modelling the electric field distribution within a piece of glass and fluorine-doped tin oxide coated glass substrate (FTO) both of which were placed inside the alumina casket with SiC susceptors (Fig. 5). The details of the geometry and properties used for the individual situations are as follows:

Water - To validate the simulation methodology a beaker of water was placed in the microwave oven and heated with $200 \mathrm{~W}$. This was recreated in the simulations. The beaker had an external radius of $88 \mathrm{~mm}$ and was $2 \mathrm{~mm}$ thick. The beaker had a relative permittivity of 2.5 and a loss tangent of 0.002 . The water column was a cylinder of radius $43 \mathrm{~mm}$. The water was $27 \mathrm{~mm}$ above the floor of the oven and had a height of $56 \mathrm{~mm}(83$ $\mathrm{mm}$ above the oven floor) (Fig. 3). The water had a relative permittivity of 81 ; a conductivity of $1.73 \mathrm{~S} / \mathrm{m}$ and a density of $1000 \mathrm{~kg} / \mathrm{m}^{3}$. The specific heat capacity used for water was $4181.3 \mathrm{~J} / \mathrm{kgK}$.

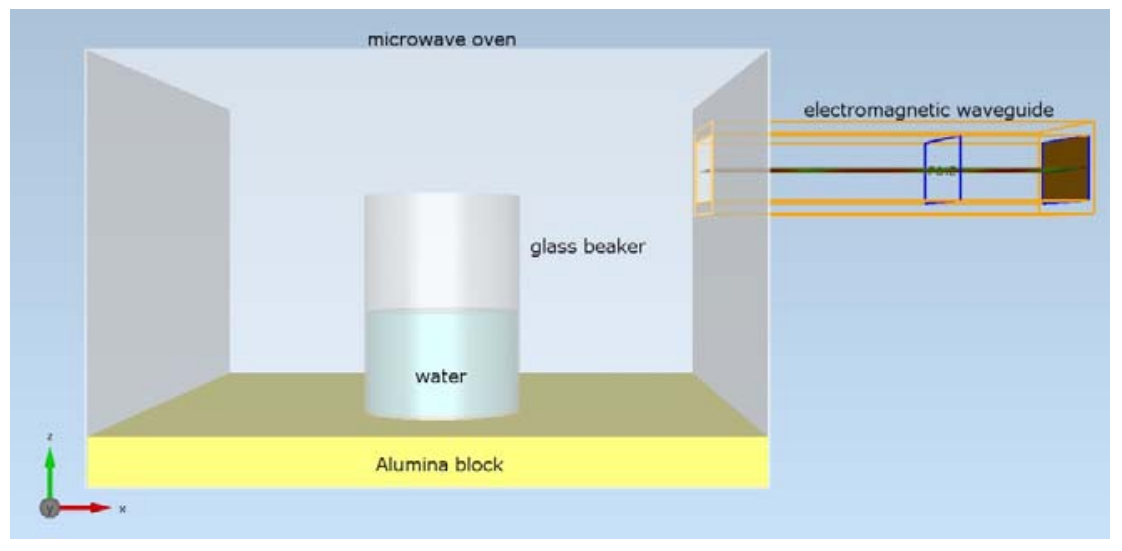

Figure 3. Schematic showing the geometry used for water simulations. 
Final author version:

Elsevier Applied Surface Science, vol. 275, no. June, pp. 65-70, 2013.

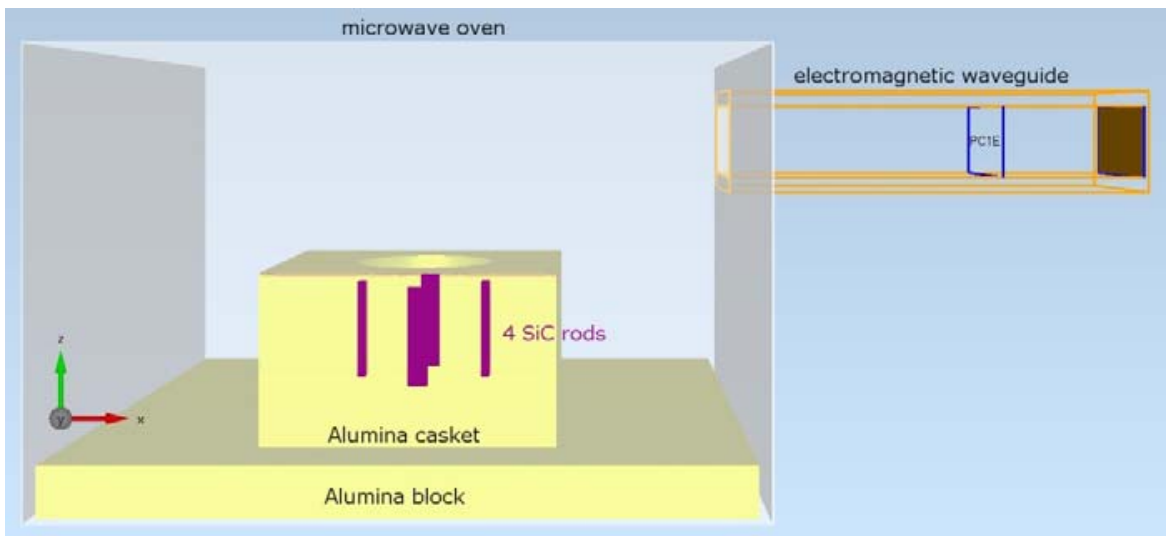

Figure 4. Schematic showing the geometry used for SiC simulations.

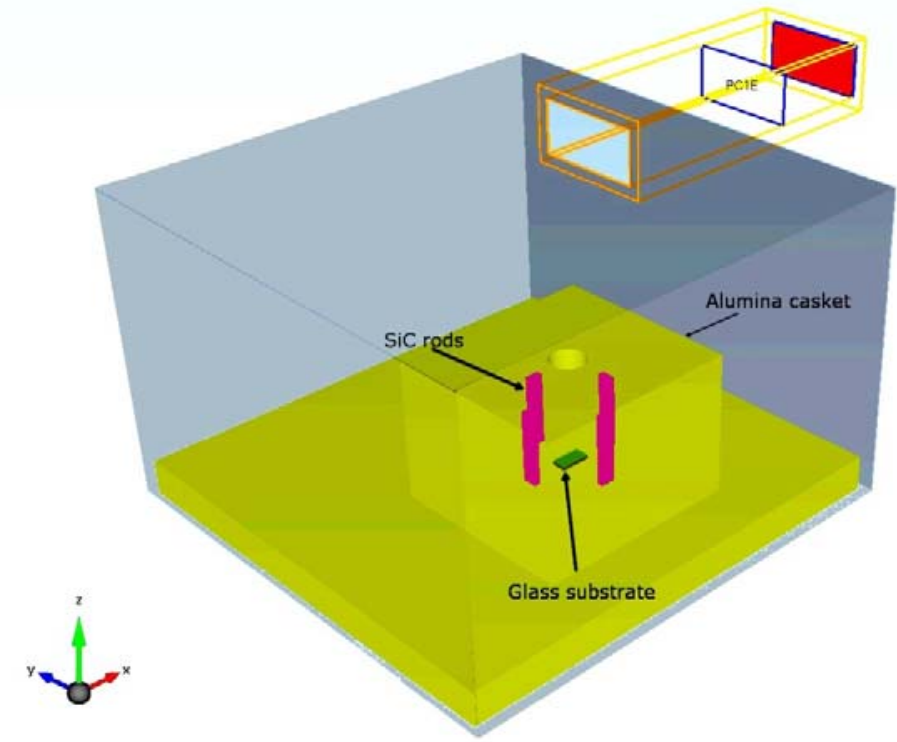

Figure 5. Schematic showing the geometry used for glass and FTO simulations.

SiC - As a second comparison with measured results, 4 silicon carbide secondary susceptors were simulated. As mentioned earlier, $\mathrm{SiC}$ rods were placed inside a high purity alumina casket not only to minimise the heat loss but also to replicate similar configurations used in our previous study to fabricate nanostructured hematite electrodes [16]. The 4 rods were placed in a $70 \mathrm{~mm}$ diameter cylindrical hole in a block of porous alumina. The geometry of the rods were cuboid: $50 \mathrm{~mm}$ high $\times 4 \times 10 \mathrm{~mm}$ (Fig. 4). The 


\section{Final author version:}

Elsevier Applied Surface Science, vol. 275, no. June, pp. 65-70, 2013.

properties of silicon carbide used were: relative permittivity $=16$; conductivity $=1.745$

$\mathrm{S} / \mathrm{m}$; density $=3210 \mathrm{~kg} / \mathrm{m}^{3}$ and specific heat capacity $=690 \mathrm{~J} / \mathrm{kgK}[35]$.

Glass and FTO substrates- The distribution of electric field in glass and FTO coated glass substrates were also simulated. The substrates were placed inside the alumina casket and $4 \mathrm{SiC}$ susceptors were positioned around them (Fig. 5). The dimensions of glass substrate were $2 \mathrm{~mm}$ thick, $10 \times 20 \mathrm{~mm}$. The FTO layer thickness was $1 \mathrm{~mm}$ and this layer in placed on top of the glass substrate (i.e. the total thickness was $3 \mathrm{~mm}$ ). The properties of glass used were: relative permittivity $=4.82$; conductivity $=0.0035 \mathrm{~S} / \mathrm{m}$; density $=2600 \mathrm{~kg} / \mathrm{m}^{3}$ and specific heat capacity $=750 \mathrm{~J} / \mathrm{kgK}$. The properties of FTO layer used were: permittivity $=3.7$; conductivity $=10000 \mathrm{~S} / \mathrm{m}$; density $=6950 \mathrm{~kg} / \mathrm{m}^{3}$ and specific heat capacity $=40.5 \mathrm{~J} / \mathrm{kgK}$.

\section{Results and discussion}

Simulation of water heating - Water was used as a simple system with known dielectric properties to establish and evaluate the accuracy of the numerical simulations. Simulation of microwave heating of water for different applications such as drying and food processing has been carried out extensively [36-38]. The heating characteristics depend on many different factors, such as waveguide geometry, frequency, water layer thickness and position within the heating chamber, therefore the results of the simulations become system specific.

The electric field distributions in microwave heated water were not found to be uniform (Fig. 6). This is because the dimensions of the water are of the same order of magnitude as a wavelength hence resonances would occur [5]. The electric field magnitudes also varied as a function of the height in the liquid with the maximum electric fields occurring roughly half way up the water as expected. Note, the software uses a standard electric field magnitude and the results need to be scaled to $200 \mathrm{~W}$ after the simulation is finished. Once the electric fields have been calculated, the temperature increase per second can be calculated from Equation (3). 
Final author version:

Elsevier Applied Surface Science, vol. 275, no. June, pp. 65-70, 2013.

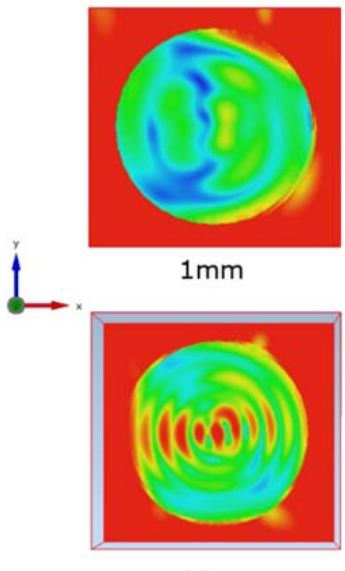

$20 \mathrm{~mm}$

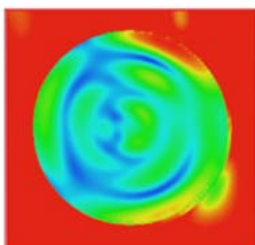

$3 \mathrm{~mm}$

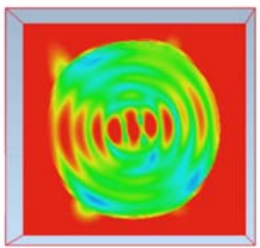

$30 \mathrm{~mm}$

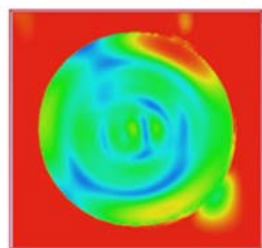

$5 \mathrm{~mm}$

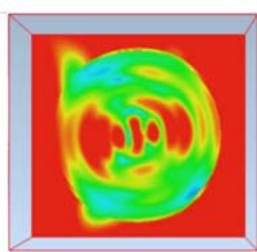

$40 \mathrm{~mm}$

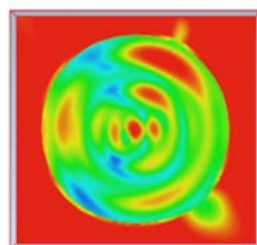

$10 \mathrm{~mm}$

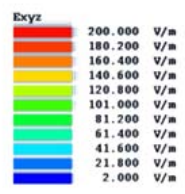

Figure 6. Distribution of electric field at different depths below the surface of the water (6.6 W input). Note that to show the results in the water more clearly, the maximum scale is fixed to $200 \mathrm{~V} / \mathrm{m}$. Therefore, the electric fields outside the water are greater than $200 \mathrm{~V} / \mathrm{m}$.

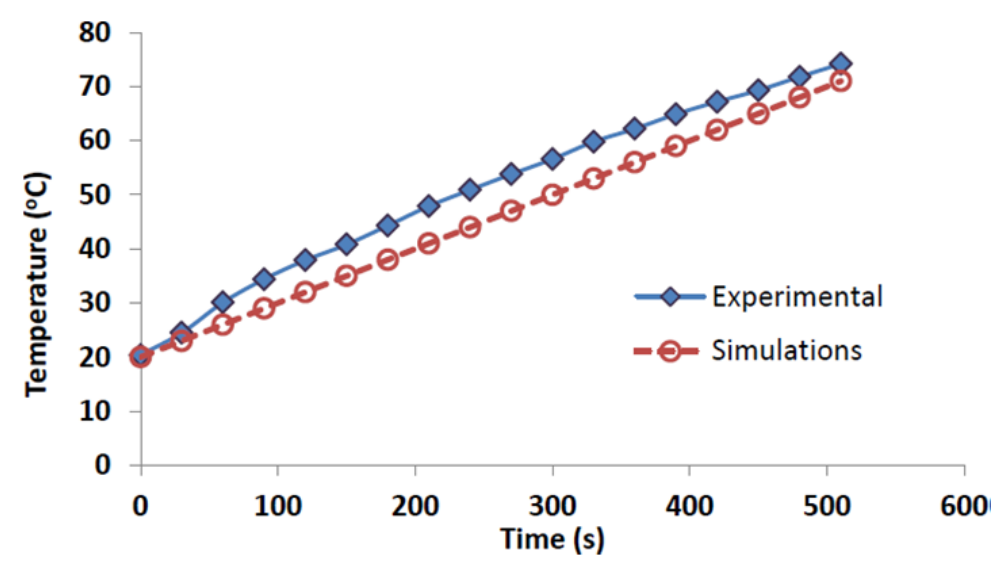

Figure 7. Comparison between experimental and simulated temperature values for water as a function of time under $200 \mathrm{~W}$ microwave power.

Near the top of the water, the calculated heating rate is 0.02 degrees per second. The SAR averaged over a layer at the centre of the water equate to a temperature increase rate of 0.17 degrees / $\mathrm{s}$. When the SAR is averaged over the entire volume of the water, the temperature increase rate is 0.09 degrees/s which agrees well with the measured values (Fig. 7). One of the main factors for the observed slight difference between simulated and 


\section{Final author version:}

Elsevier Applied Surface Science, vol. 275, no. June, pp. 65-70, 2013.

experimental results is the fact that thermal conduction and convection has not been taken into account in the simulations.

Simulation of SiC heating - The simulated electric fields within the silicon carbide rods varied as a function of height. The calculated temperature increase rate varied across the $4 \mathrm{SiC}$ rods. Averaged over all four rods, the absorbed electric fields increased the temperature of the silicon carbide by 0.45 degrees/s. As shown in Fig. 8, the difference between the temperatures measured by the thermal imaging camera and simulation results increases as the temperature increases. This can be explained by the fact that material properties such as conductivity are dependent on the material properties. This has not been considered in the modelling procedure. Furthermore, the other factors which are not considered here are the convection and conduction heat transport which will have significant effects on the calculated temperatures.
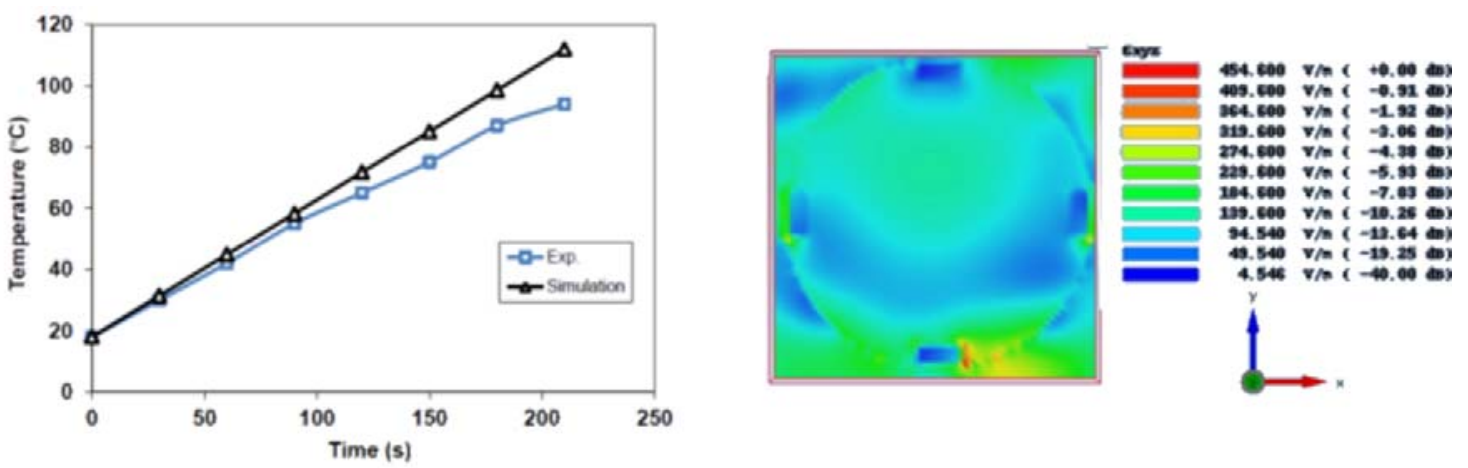

Figure 8. Comparison of experimental and simulated temperature of the $\mathrm{SiC}$ rods (left). The distribution of electric field at $0.6 \mathrm{~W}$ power input at $5 \mathrm{~mm}$ below the surface of the $\mathrm{SiC}$ rods (right).

Simulation of glass and FTO substrates heating - The electric field distribution obtained from modelling is shown in Fig. 9. The highest electric field observed in glass substrate was around $2 \mathrm{kV} / \mathrm{m}$ at the centre of the glass. The average SAR value in the glass was approx. $5.2 \mathrm{~W} / \mathrm{kg}$ (for $200 \mathrm{~W}$ power) which led to $0.007^{\circ} \mathrm{C} / \mathrm{sec}$ temperature increase. This is in line with the properties of glass being an insulator and it is not expected to be heated significantly in the microwave oven.

The FTO layer coated on glass is a conductive material and hence should behave differently to glass substrate under microwave irradiation. The highest electric field 


\section{Final author version:}

Elsevier Applied Surface Science, vol. 275, no. June, pp. 65-70, 2013.

observed in glass substrate was around $0.1 \mathrm{~V} / \mathrm{m}$ at the centre of the glass. This is expected since the FTO layer is highly conductive. Therefore it behaves like a metal and the electric fields are extremely small inside. The minimum resolution of the electric field distribution in Fig. 8 is above the values observed in the FTO layer hence the changes cannot be seen in this figure. The average SAR value in the glass was approx. $40.5 \mathrm{~W} / \mathrm{kg}$ (for $200 \mathrm{~W}$ power) which led to $0.11^{\circ} \mathrm{C} / \mathrm{sec}$ temperature increase, more than 16 times higher than that of the glass substrate.
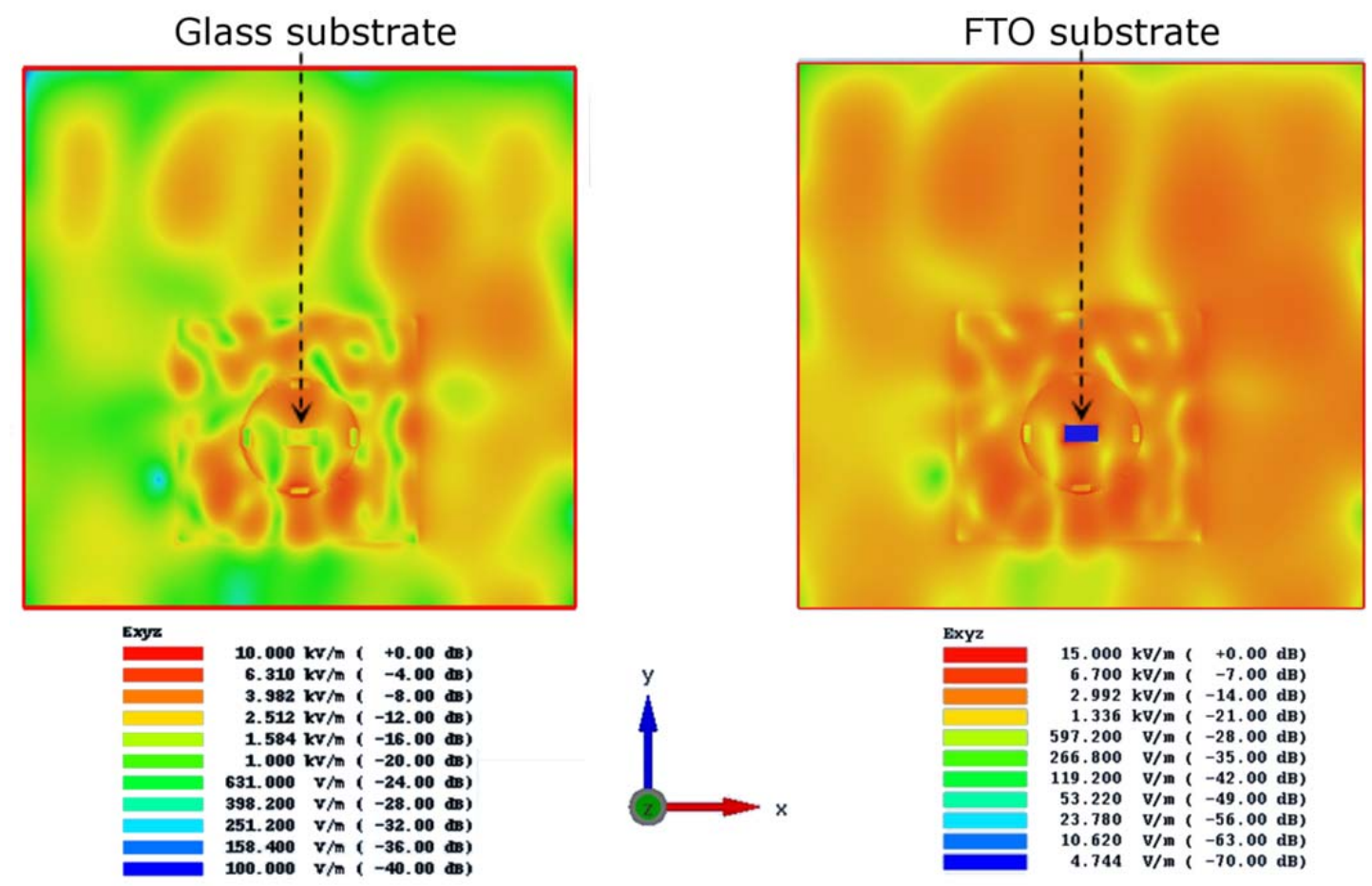

Figure 9. The distribution of electric field at the surface of the glass and also FTO substrate at $200 \mathrm{~W}$ power input.

The simulation results presented in this paper are preliminary steps that will enable the broader goal of modelling nanostructured hematite electrodes under microwave irradiation. More sophisticated modelling work is required to successfully simulate EM field distribution within nanostructured thin films as there are challenges (associated with the simulation of EM fields inside thin films) such as the need for very small Yee cells and the associated requirements of prodigious computational resources, subject of further investigation. The simulations presented herein did not take into account the heat transfer 


\section{Final author version:}

Elsevier Applied Surface Science, vol. 275, no. June, pp. 65-70, 2013.

through conduction and convection due to technical limitations of the software. However, recently a more comprehensive version has been procured and the incorporation of the conduction and convection mechanisms are underway. Successful simulation results can help to design optimum experiment conditions such as microwave power and temperature so that a better control is applied during the processing which could in turn result in tailoring the nanostructure of the films hence obtaining improved photoelectrodes.

\section{Conclusions}

The distribution of the electromagnetic (EM) fields within 4 different materials, namely water, $\mathrm{SiC}$, glass and FTO, was analysed using finite-difference time-domain (FDTD) EM software. The simulation results obtained for water and $\mathrm{SiC}$ were validated by experimental temperatures measured using a thermal imaging camera under microwave irradiation. The rate of temperature increase obtained from simulation found to be in good agreement with experimental values. Further work is underway to include the effects of conduction and convection on the heating mechanisms and use of smaller Yee cells to mimic the nanostructured hematite films with a view to understand microwavematerial interactions better.

\section{References}

[1] A. Fujishima., K. Honda, Nature 238 (1972) 37-38.

[2] P. Kamat, J. Phys. Chem. C 111 (2007) 2834-2860.

[3] R. Dholam, N. Patel, M. Adami, A. Miotello, Int. J. Hydrogen Energy 33 (2008) 6896-6903.

[4] A. Kudo, Int. J. Hydrogen Energy, 31 (2006) 197-202

[5] A. Deshpande, N. M. Gupta, Int. J. Hydrogen Energy, 35 (2010) 3287-3296.

[6] J.F. Reber, M. Rusek, J. Phys. Chem. 90 (1986) 824-834.

[7] H. Wang, T. Lindgren, J. He, A. Hagfeldt, S.-E. Lindquist, J. Phys. Chem. B 104 (2000) 5686-5696.

[8] B. Yang, P.R.F. Barnes, W. Bertrama, V. Luca, J. Mater. Chem. 17 (2007) 27222729 . 


\section{Final author version:}

Elsevier Applied Surface Science, vol. 275, no. June, pp. 65-70, 2013.

[9] V.R. Satsangi, S. Kumari, A.P. Singh, R. Shrivastav, S. Dass, Int. J. Hydrogen Energy 33 (2008) 312-318.

[10] W. B. Ingler Jr., S. U.M. Khan, Int. J. Hydrogen Energy 30 (2005) 821-827.

[11] R. van de Krol, Y. Liang, J. Schoonman, J. Mater. Chem. 18 (2008) 2311-2320.

[12] X. C. Wang, K. Maeda, A. Thomas, K. Takanabe, G. Xin, J. M. Carlsson, K. Domen and M. Antonietti, Nat. Mater. 8 (2009) 76-80.

[13] F. Dong, L. Wu, Y. Sun, M. Fu, Z. Wu and S. C. Lee, J. Mater. Chem. 21 (2011) 15171-15174.

[14] S. Saremi-Yarahmadi, A.A. Tahir, B. Vaidhyanathan, K.G.U. Wijayantha, J. Phys. Chem. C 113 (2009) 4768-4778.

[15] A. Kleiman-Shwarsctein, M.N. Huda, A. Walsh, Y. Yan, G.D. Stucky, Y.-S. Hu, M.M. Al-Jaseem, and E.W. McFarland, Chem. Mater. 22 (2010) 510-517.

[16] S. Saremi-Yarahmadi, B. Vaidhyanathan, and K.G.U. Wijayantha, Int. J. Hydrogen Energy 35 (2010) 10155-10165.

[17] C.J. Sartoretti, B.D. Alexander, R. Solarska,W. A. Rutkowska, J. Augustynski, and R. Cerny, J. Phys. Chem. B, 109 (2005) 13685-13692.

[18] J.H. Kennedy, and K.W. Frese, J. Electrochem. Soc. 125 (1978) 709-714.

[19] K.J. Rao, B. Vaidhyanathan, M. Ganguli, P.A. Ramakrishnan, Chem. Mater. 11 (1999) 882-895.

[20] X. Hu, J.C. Yu, J. Gong, Q. Li, G. Li, Adv. Mater. 19 (2007) 2324-2329.

[21] R.G. Deshmukh, S.S. Badadhe, I.S. Mulla, Mater. Res. Bull. 44 (2009) 1179-1182.

[22] J.-Y. Hwang, S. Shi, Z. Xu, K.W. Peterson, Chem. Eng. Comm. 193 (2006) 15861591.

[23] B. Vaidhyanathan, S. Saremi-Yarahmadi, U. Wijayantha, Ceramic Engineering and Science Proceedings, 32 (2011) 11-20.

[24] A. Taflove, Computational electrodynamics. The finite-difference time-domain method. Artech House, Inc., 1995.

[25] W. G. Whittow, "Specific absorption rate perturbations in the eyes and head by metallic spectacles at personal radio communication frequencies," $\mathrm{PhD}$ thesis EEE Dept. University of Sheffield, UK, 2004. 
Final author version:

Elsevier Applied Surface Science, vol. 275, no. June, pp. 65-70, 2013.

[26] S. Watanabe, M. Karakawa, and O. Hashimoto, Flux, 58 (2010) 1196-1204.

[27] S. Hanafusa, T. Iwaski, and N. Nishimura, in Antennas and Propagation Society International Symposium, 1994. AP-S. Digest, 1994, pp. 1806-1809.

[28] E. M. Kiley and V. V. Yakovlev, in Symposium Digest (MTT), 2011 IEEE MTT-S International, 2011, pp. 1-4.

[29] S. Watanabe, Y. Kakuta, and O. Hashimoto, IEEE MTT-S Intl. Microw. Symp. 2 (2006) 284-287.

[30] M. F. Iskander, R. L. Smith, A. O. M. Andrade, H. Kimrey, L. M. Walsh, IEEE Trans. Microw. Theory Tech. 42 (1994) 793-800.

[31] F. I. Friedlander, H. W. Jackson, M. Barmatz, P. Wagner, in Microwave Processing of Materials V, Materials research Society Symposium Proceedings, 430 (1996) 333-337. [32] D. C. Dibben, W.B. Fu, A. C. Metaxas, in Microwave Processing of Materials IV, Materials research Society Symposium Proceedings, 347 (1994) 305-310.

[33] W. G. Whittow and R. M. Edwards, IEEE Trans. Antennas and Propagation, 52 (2004) 3207-3212.

[34] W. G. Whittow, C. J. Panagamuwa, R. M. Edwards, and J. C. Vardaxoglou, Phys. Med. Biol. 53 (2008) 1167-1182.

[35] Y. Takeuchi, K. Akai, N. Akasaka, E. Ezura, T. Kageyama, H. Mizuno, F. Naito, H. Nakanishi, H. Sakai, Y. Yamazaki, Proc. of Particle Accelerator Conf. PAC97, Vancouver (1997), 2986-2988.

[36] P. Rattanadecho, W. Klinbun, J. Heat Transfer, 133 (2001) 031008-1- 10.

[37]Q. Zhang, T. H. Jackson, A. Ungan, Int. J. Heat Mass Transfer, 43 (2000) 2141-2154.

[38] W. Cha-um, P. Rattanadecho, W. Pakdee, Food Bioprocess Technol., 4 (2011) 544 558. 